\title{
Application of the AAV-Syn-BDNF-EGEP Virus Vector as a Neuroprotective Agent in Modeling Hypoxia in vitro
}

\author{
DOI: $10.17691 / \mathrm{stm} 2018.10 .2 .05$
}

Received January 19, 2018

E.V. Mitroshina, PhD, Associate Professor, Department of Neurotechnologies,

Institute of Biology and Biomedicine ${ }^{1}$; Senior Researcher, Laboratory for Neuroprotection Methods Development, Center for Translational Technologies'; Senior Researcher, Molecular Cellular Technologies Department, Central Scientific Research Laboratory";

E.A. Epifanova, Junior Researcher, Brain Development Genetics Laboratory, Institute of Neuroscience ${ }^{1 ;}$ T.A. Mishchenko, PhD, Senior Researcher, Laboratory for Neuroprotection Methods Development, Center for Translational Technologies'; Senior Researcher, Molecular Cellular Technologies Department, Central Scientific Research Laboratory²;

R.S. Yarkov, MSc, Department of Neurotechnologies, Institute of Biology and Biomedicine ${ }^{1 ;}$

A.A. Babaev, PhD, Associate Professor, Department of Neurotechnologies, Institute of Biology and Biomedicine"; Senior Researcher, Brain Development Genetics Laboratory, Institute of Neuroscience"; M.V. Vedunova, DSc, Leading Researcher, Director of Institute of Biology and Biomedicine ${ }^{1}$

'Lobachevsky State University of Nizhni Novgorod, 23 Prospekt Gagarina, Nizhny Novgorod, 603950,

Russia;

${ }^{2}$ Privolzhsky Research Medical University, 10/1 Minin and Pozharsky Square, Nizhny Novgorod, 603005,

Russia

The aim of the study was to develop the AAV-Syn-BDNF-EGFP virus vector and study its effect on primary cultures in normal conditions and under hypoxia in vitro.

Materials and Methods. To produce the virus construct, AAV-Syn-EGFP, pDP5, DJ vector, and pHelper plasmids were used. The developed vector was tested on primary hippocampal cells obtained from C57BL/6 mouse embryos on the embryonic day 18 (E18). Infection of primary cultures with the developed virus construct was carried out on the $7^{\text {th }}$ day of culture development in vitro (7 DIV). The cell viability and spontaneous bioelectrical activity of the cultured cells were assessed on days 1, 3, and 7 after infection. On the $7^{\text {th }}$ day after infection (14 DIV), spontaneous calcium activity of dissociated cultures was analyzed using functional calcium imaging. To evaluate the neuroprotective properties of the developed construct, in vitro hypoxia modeling was performed on the $14^{\text {th }}$ day (14 DIV) of cultivation.

Results. The AAV-Syn-BDNF-EGFP adeno-associated virus vector carrying the sequence of the BDNF gene has been developed to increase this neurotrophin expression. Primary hippocampal cells infected by the vector were found to produce increased amounts of BDNF. The developed virus vector did not adversely affect the viability and functional activity of the neural networks in the primary hippocampal cultures. The BDNF overexpression enhanced the neuroprotective potential of cells subjected to oxygen deficiency.

Conclusion. The developed virus containing the BDNF gene sequence increases the endogenous BDNF expression by brain neurons, and thus reduces the death rate of nerve cells in the hypoxia model in vitro.

Key words: genetically engineered constructs; adeno-associated virus vectors; brain-derived neurotrophic factor; BDNF; cerebral ischemia; cerebral hypoxia; primary hippocampal cell cultures; neuroprotection.

\section{Introduction}

Ischemic stroke is characterized by severe damage to the central nervous system (CNS) after a short or prolonged occlusion of cerebral blood vessels. Currently, an active research into the effective strategies for the prevention and therapy of ischemic brain damage, and the ways to maintain the functional activity of neural networks are actively pursued. It should be noted that ischemic brain damage is a multifactorial disease.
Hypoxia (oxygen deprivation), a decrease in the supply of energy substrates (glucose deprivation), and oxidative stress are the key detrimental factors of failed blood supply to the brain.

It has been shown [1-4] that an effective approach to correcting the ischemic brain damage is the use of the brain-derived neurotrophic factor (BDNF). This factor represents the family of neurotrophins - a key element in the brain embryogenesis and the subsequent postnatal period $[5,6]$. BDNF is involved in the

Corresponding author: Elena V. Mitroshina, e-mail: helenmitroshina@gmail.com 
modulation of synaptic transmission in the hippocampus and certain parts of the cerebral cortex [7-10]. Numerous studies indicate that exogenous neurotrophin increases the resistance of nerve cells to ischemic damage both in vitro and in vivo [11-14]. BDNF reduces neuronal death, limits the stroke volume, and accelerates neurological and cognitive recovery in post-ischemic animals [15, 16]. Another interesting feature of BDNF is its ability to preserve the neurons that are not part of neural networks in early ontogeny. Thanks to this effect of BDNF, in the post-ischemic period, those neurons that have lost their connections with other neurons remain alive.

One of the promising areas of today's medical research is the development of biotechnological technologies that allow for delivery to the body of various neuroprotective compounds including virus vectors for gene therapy. This approach results in an increase in the level of the desired protein that lasts for a long time; this technology targets a strictly defined type of cells and allows one to avoid using a long-term drug therapy. Today the options of using virus vectors to deliver the $B D N F$ gene to nerve cells in neurodegenerative diseases and neuro-traumas are actively studied. For example, Liu et al. [17] showed that the adeno-associated virus vector carrying the BDNF gene stimulates the growth of axons after a spinal cord injury. Others demonstrated favorable effects of the virus BDNF vector systems in retinal degeneration [18, 19], in Friedrich's ataxia [20] and in Alzheimer's disease [21]. However, there are reports showing difficulties of using such delivery methods. For example, in the work of Dekeyster et al. [22], no overexpression of BDNF was achieved after an attempted virus delivery in glaucoma.

Despite this, the initiation of BDNF expression with the help of a virus can be viewed as a new approach to the development of effective therapy of cerebral ischemic stroke. Such research is now at its initial stage worldwide. There are examples of a successful use of the modified AAV-BDNF virus [23]. When administered into the sub-ventricular zone of adult rats 14 days before an induced occlusion of the right middle cerebral artery, this treatment improved the recovery of the locomotor function after a stroke. This effect could be associated with an increased migration of neuro-progenitors in the brain of the experimental animals.

The aim of the study was to develop the AAV-SynBDNF-EGFP virus vector and study its effect on primary cultures of normal hippocampal cells and the cells under hypoxia in vitro. (The hypoxia model simulated the major factor of ischemia, i.e. ischemic hypoxia).

\section{Materials and Methods}

Plasmids. We utilized plasmids AAV-Syn-EGFP, pDP5, DJvector, and pHelper to develop the sought virus construct. The AAV-Syn-EGFP plasmid is derived from the bacterial pUC19 plasmid; it carries the sequences of the human synapsin (hSyn) promoter, the WPRE enhancer, and the SV40 polyA signal sequence flanked by the inverted terminal repeats (ITR) from the adenoassociated serotype 2 virus (AAV2). The other three plasmids (pDP5, DJvector, and pHelper) are helper plasmids required to assemble the adeno-associated virus vector that carries the Rep, Cap genes.

Isolation of total RNA. Isolation of total RNA from biological samples (mouse brain tissue) for subsequent production of cDNA encoding the BDNF protein was carried out according to the standard protocol using the Extract RNA reagent (Evrogen, Russia).

Polymerase chain reaction (PCR). A commercial kit of Phusion High-Fidelity PCR Kit containing Phusion High-Fidelity DNA polymerase (Thermo Fisher Scientific, USA) was used to carry out the PCR for the generation of cloned fragments of the BDNF gene. The advantage of this polymerase is its high activity and accuracy. The reverse transcription PCR was performed using a MMLV reverse transcriptase (Evrogen, Russia).

Plasmid cloning. Purification of the resulting BDNF sequence was performed using the commercial Isolate II PCR and Gel Kit (Bioline, UK) according to the manufacturer's protocol. For the construction of the plasmid, enzymes from Thermo Fisher Scientific (USA) and New England BioLabs (USA) were used. Restriction of the cloned BDNF fragment and AAV-Syn-EGFP-kid2 plasmid was performed with EcoRI and BamHI restriction enzymes to form sticky ends (Figure 1). A ligase mixture was further used to transform competent E. coli TopTEN cells.

Transformation of E. coli bacterial cells plasmid DNA, generation, and isolation of plasmid DNA. The competent cells of $E$. coli TopTEN were used for the transformation. The bacterial cells were kept on ice for 15-20 min, after which the plasmid cloned AAV-SynBDNF-EGFP was added in a volume of $1 / 10$ of the cell volume and the mixture was incubated for $20 \mathrm{~min}$ on ice. The cells were then subjected to heat shock at $42^{\circ} \mathrm{C}$ for $45 \mathrm{~s}$ in a water bath and incubated on ice for $3 \mathrm{~min}$.

After a $30-90$-minute incubation at $37^{\circ} \mathrm{C}$ under continuous shaking (200-300 rpm) in a three-fold volume of the SOB medium for the cultivation of prokaryotic cells, the transformed cells were plated on Petri dishes containing LB medium (Luria-Bertani), agar and ampicillin $(100 \mu \mathrm{g} / \mathrm{ml})$. Cultivation on the plates was carried out at $37^{\circ} \mathrm{C}$ for $12-16 \mathrm{~h}$, after which a part of the obtained bacterial colonies was further grown in liquid mini- and maxi-cultures. Then plasmid DNA was isolated using commercial sets of ISOLATE II Plasmid Mini Kit (Bioline, UK) and NucleoBond Xtra Midi/Maxi (MACHEREY-NAGEL, Germany) according to the manufacturer's protocol.

Cultivation of the human embryonic kidney cell line HEK 293T and transfection. The conditions for the cultivation of the HEK 293T cell line were identical to those indicated in the culture certificate: DMEM; $10 \%$ bovine embryonic serum; $15 \mu \mathrm{g} / \mathrm{ml}$ gentamicin. The passage procedure: the cell removal with $0.25 \%$ trypsin 


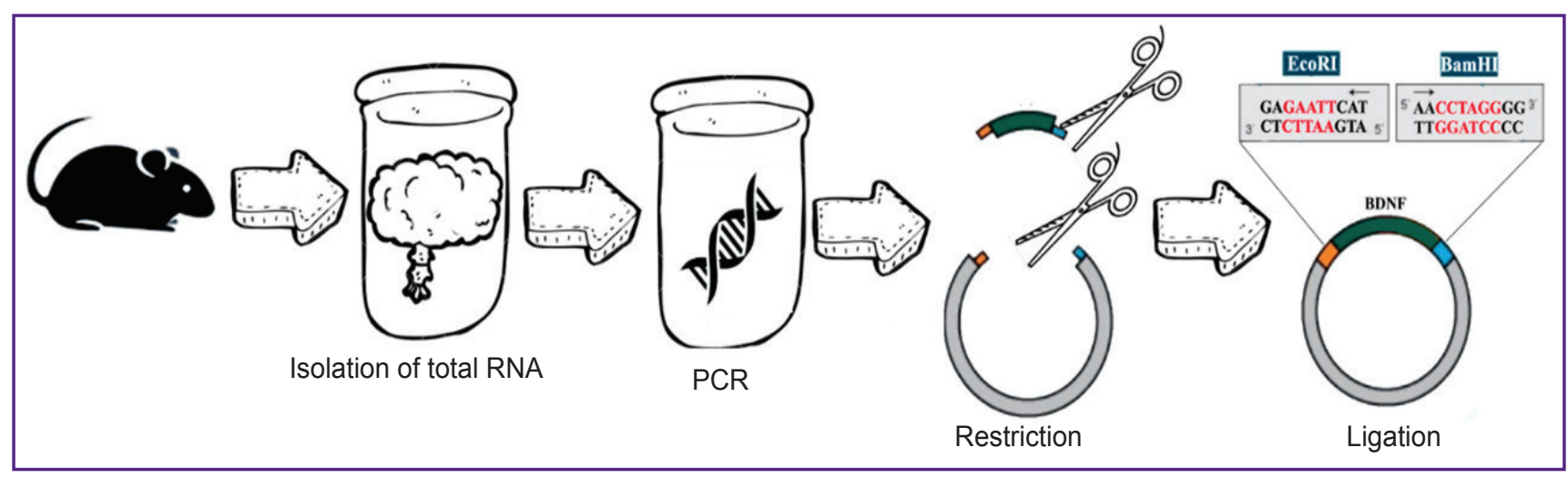

Figure 1. The technique used to clone the fragment of the BDNF gene into a shuttle plasmid

and $0.02 \%$ Versene $(1: 2-1: 3)$, the seeding ratio of $1: 2-1: 3$, and the optimal density (3.0-5.0) $10^{4}$ cells $/ \mathrm{cm}^{2}$. Cultivation was carried out in a $\mathrm{CO}_{2}$ incubator at $37^{\circ} \mathrm{C}$, $5 \% \mathrm{CO}_{2}, 80 \%$ humidity.

The shuttle plasmid AAV-Syn-BDNF-EGFP and the helper plasmids pDP5, DJvector, pHelper were used for HEK transfection. The expression and helper plasmids were mixed in equimolar amounts (20 $\mu \mathrm{g}$ each) with the DMEM culture medium. A mixture of PEI/DMEM was added to the DNA/DMEM mixture and incubated for $15 \mathrm{~min}$ at room temperature, after which the volume of DMEM was adjusted to $15 \mathrm{ml}$. The culture medium of HEK 293T was replaced with a mixture of PEI/DNA/ DMEM for $4-5 \mathrm{~h}$ at $37^{\circ} \mathrm{C}, 5 \% \mathrm{CO}_{2}$. After this, a complete replacement of the medium with DMEM containing $2 \%$ serum was performed and the cells were incubated for $3-5$ days at $37^{\circ} \mathrm{C}, 5 \% \mathrm{CO}_{2}$.

Isolation and purification of adeno-associated virus particles. After transfection, the HEK 293T cells were removed from the substrate using phosphate buffered saline (PBS) containing no $\mathrm{Ca}^{2+}$, no $\mathrm{Mg}^{2+}$, then centrifuged at $1000 \mathrm{rpm}$ for $5 \mathrm{~min}$, and the precipitate dissolved in $2 \mathrm{ml}$ of lysis buffer. The lysate was subjected to a freeze/thaw cycle $\left(-80^{\circ} \mathrm{C}\right)$ three times. After the final thawing, the cell lysate was centrifuged at $2000 \mathrm{rpm}$ for 5 min. Then, an enzymatic treatment with benzonase was performed to remove nucleotides and nucleic acids not protected by the virus capsid, centrifuged at 2000-2500 rpm for $5 \mathrm{~min}$ to sediment various protein granules and debris of large molecules, after which the supernatant was filtered through a $0.45 \mu \mathrm{m}$ filter. Additional purification and concentration of the virus preparation were carried out using Amicon Ultra-15 columns (Millipore, UK).

Cultivation of dissociated hippocampal cells. The below studies were conducted on cultures of dissociated hippocampal cells obtained from E18 embryos of C57BL/6 mice. We followed the basic rules for the maintenance and care of experimental animals according to the Rules for the Work using Experimental Animals (Russia, 2010) and International Guiding Principles for
Biomedical Research Involving Animals (CIOMS and ICLAS, 2012); the ethical principles established by the European Convention for the Protection of Vertebrate Animals used for Experimental and Other Scientific Purposes (Strasbourg, 2006). The permission to carry out experimental studies on animals was obtained from the Ethics Committee of the Lobachevsky State University of Nizhni Novgorod.

Enzymatic dissociation of embryonic hippocampal cells was carried out with a $0.25 \%$ trypsin solution (Gibco, USA). Culturing of primary cultures was performed in the Neurobasal ${ }^{\mathrm{TM}}$ medium (Thermo Fisher Scientific, USA) complexed with the B27 bioactive additive (Thermo Fisher Scientific, USA), L-glutamine (Thermo Fisher Scientific, USA), fetal calf serum (PanEko, Russia) according to the previously developed protocol [24] for 21 days on glasses coated with polyethyleneimine (Sigma, USA) to enhance the adhesion of cells to the surface. The initial density of the culture cells on the matrix was 9000 cells $/ \mathrm{mm}^{2}$. The cultures were maintained in a $\mathrm{CO}_{2}$ incubator (MCO$18 \mathrm{AIC}$, Sanyo, Japan) at $35.5^{\circ} \mathrm{C}$ and a gas mixture containing $5 \% \mathrm{CO}_{2}$.

Immunocytochemistry. Primary polyclonal chicken antibodies to BDNF and secondary polyclonal antibodies conjugated with a fluorescent label - Goat antiChicken IgY H\&L (Alexa Fluor 647) (Abcam, USA) were used in the test. Cell cultures were fixed in a $4 \%$ solution of paraformaldehyde in PBS for $20 \mathrm{~min}$ at room temperature; a solution of $0.2 \%$ Triton X-100/PBS was used for cell permeabilization. It was performed the imaging of stained material using a Zeiss 510 NLO fluorescent confocal microscope (Carl Zeiss, Germany).

Modeling of hypoxia (14 DIV) was performed by replacing the culture medium with a low oxygen medium for $10 \mathrm{~min}$. Oxygen was removed by saturation of the culture medium with argon. The experiment was carried out in a sealed chamber, where air was also replaced by argon.

Evaluation of cell viability in dissociated hippocampal cultures. Cell viability was assessed on days 1, 3, and 
7 after the developed virus construct was added to the cells, and also day 7 after the hypoxia modeling. For this purpose, the number of cell nuclei stained with propidium iodide (Sigma, USA) (dead cells), and the nuclei stained with bis-benzimide (Sigma, USA) (all cells in culture) were counted. The cell death rate was calculated by the ratio of propidium iodide-positive to bis-benzimidepositive cells [24].

Functional calcium imaging. The metabolic activity of the hippocampal cells was evaluated with the help of calcium imaging, which reflects the changes in the concentration of cytoplasmic calcium. A specific calcium dye Oregon Green 488 BAPTA-1 acetoxymethyl ester (OGB-1 AM) (Invitrogen, USA) was used as a fluorescent probe. Staining was performed according to a standard protocol [25]. Fluorescence was recorded using a LSM 510 NLO laser scanning microscope (Carl Zeiss, Germany). The temporal images of the OGB-1 AM fluorescence field were recorded. The fluorescence was excited by an argon laser at a wavelength of $488 \mathrm{~nm}$, and recorded using a light filter with a band of $500-530 \mathrm{~nm}$. The change in fluorescence intensity (arbitrary units) of the selected vision field focused at the cell body was analyzed. Processing and analysis of calcium associated images were carried out with the help of the original software package Astroscanner (certificate of state registration of the computer program No.20114662670). The temporal function $\mathrm{F}(\mathrm{t})$ - the average OGB-1 AM fluorescence intensity - in the selected field versus time was also analyzed. The following parameters were taken into account: the duration (s), the frequency (number of calcium events/min), and the percentage of active cells in the culture [25].

Analysis of bioelectric activity. To study the changes in spontaneous bioelectrical activity, multielectrode matrices MEA 60 (Multichannel Systems, Germany) and a set of Conductor ${ }^{\mathrm{TM}}$ software (Alpha Med Scientific, Japan) were used. Recording of the extracellular action potentials (7 DIV) was carried out before the addition of the virus construct; then the test was run daily for 7 days. The spikes (extracellular action potentials) were detected and recorded according to the following algorithm. A boundary of $8 \sigma$ was chosen, where $\sigma$ is the root-mean-square deviation. If the spontaneous peak exceeded the given threshold, the event was considered a spike; if the peak did not exceed the threshold it was recognized a noise and was not counted. The criterion of the "small network packet" was the appearance of spikes at least at four different matrix electrodes with an inter-spike interval within $100 \mathrm{~ms}$. In data analysis, two major parameters were evaluated: the average number of small network packets and the average number of spikes in a small network packet. The obtained data was processed using the original package of MEAMAN algorithms developed in the MATLAB programming environment [26].

Statistical analysis. The obtained data are presented as the mean \pm standard error of the mean $(M \pm S E M)$. The significance of the differences between the experimental groups was determined using the ANOVA package in SigmaPlot 11.0 (Systat Software Inc., USA). Differences were considered statistically significant at $p<0.05$.

\section{Results}

At the first stage of this study, we attempted to increase the expression of the neurotrophic factor BDNF in the neurons. To that end, the plasmid vector carrying the coding sequence of the BDNF gene was constructed and assembled using the molecular cloning techniques. The constructed plasmid vector served the essential basis for the virus. The following sequences were included in the plasmid vector (Figure 2): 1) the human promoter of the synapsin protein (hSyn), which is a strong promoter allowing the gene of interest expression only in neuronal cells; 2) the WPRE-enhancer (woodchuck hepatitis posttranscriptional regulatory element) - a regulatory element that significantly enhances the work of the hSyn synapse promoter; 3) the multilinker for the ORF (open reading frame) cloning of the inserted gene; 4) the EGFP gene, which can be cut out by appropriate restriction enzymes, if needed; 5) the SV40 polyA signal sequence flanked by ITR repeats from the AAV of serotype 2; 6) a cassette of genes encoding the ampicillin resistance, which is necessary for the positive selection of the colonies that carry this plasmid (AmpR promoter and AmpR gene), and 7) a sequence corresponding to the nucleotide sequence encoding the BDNF functional protein.

In the study, the amplification of the neurotrophic factor BDNF was facilitated with the primer system mBDNF-EcoRI-fw and mBDNF-BamHI-rv (5'-ATTGAATTCATGGGCCACATGCTGTCC-3' and 5'-AATGGATCCAATCTTCCCCTTTTAATGGTCAGTG-3'), in which were integrated the restriction sites for subsequent restriction and ligation into the vector being constructed.

The temperature and reaction time were found out to allow for amplification of the oligonucleotide sequence of the neurotrophic factor BDNF. The initial denaturation was carried out at a temperature of $95^{\circ} \mathrm{C}$ for $1 \mathrm{~min}$. Then, the working cycle of three procedures followed, repeating 30 times: $95^{\circ} \mathrm{C}-15 \mathrm{~s}-$ denaturation, $65^{\circ} \mathrm{C}-10 \mathrm{~s}-$ primer annealing, $72^{\circ} \mathrm{C}-40 \mathrm{~s}-$ elongation. And after that, the final completion of the chains occurred at a temperature of $72^{\circ} \mathrm{C}$ for $7 \mathrm{~min}$. As a result, the coding sequence for the neurotrophic factor BDNF was obtained. The constructed plasmid was generated from $E$. coli cells, the identity of the assembly was confirmed by the restriction and $P C R$ reactions with the cloned fragment of the BDNF gene, the lengths of the fragments were electrophoretically verified (Figure 3 ).

The next stage of the work was the testing of the obtained virus vector with the primary hippocampal cultures. Using confocal microscopy we confirmed the expression of the green fluorescent EGFP protein in 
Figure 2. The map of the AAVSyn-BDNF-EGFP-kid2 plasmid (constructed using SnapGene Viewer 3.1.2)

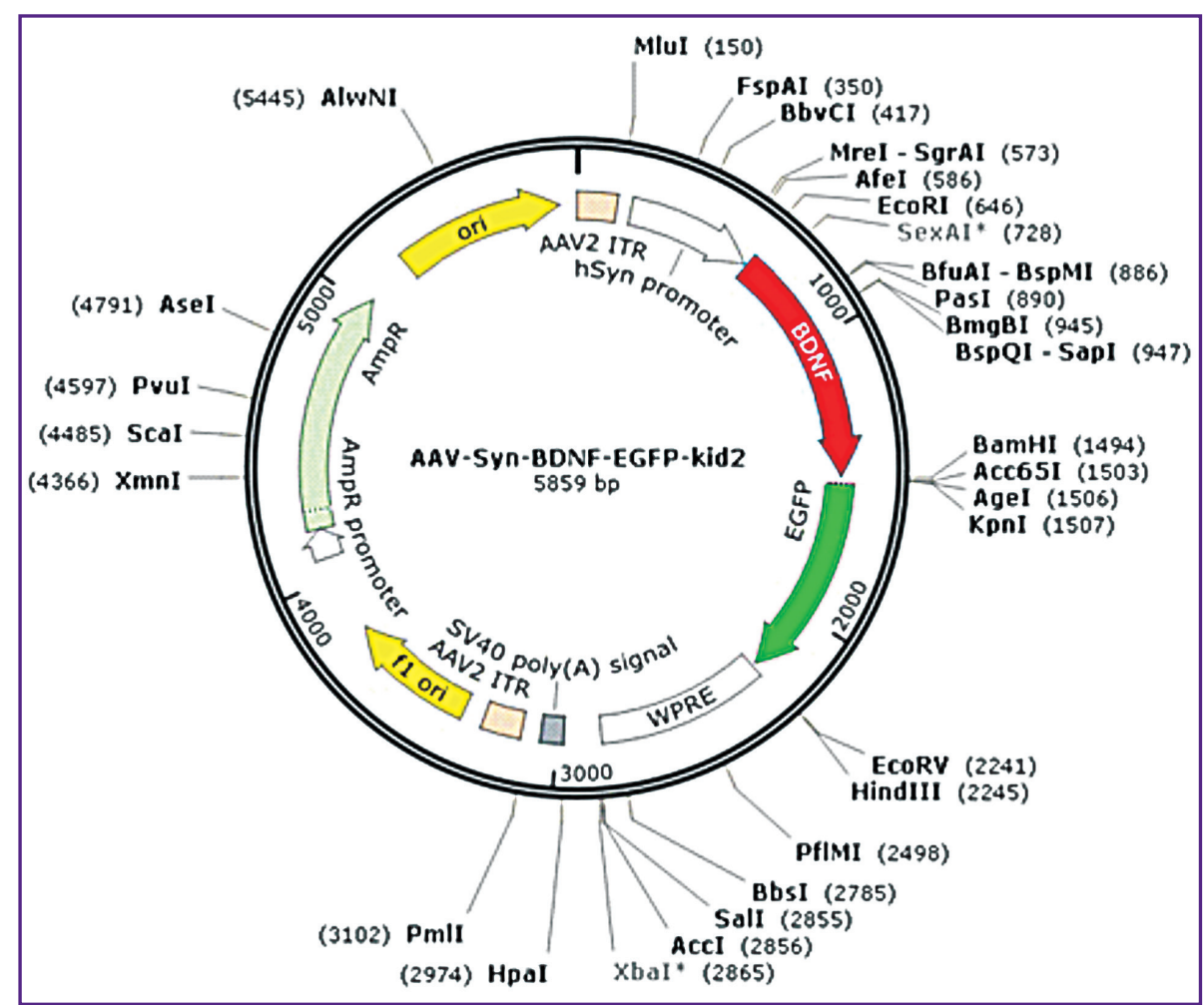

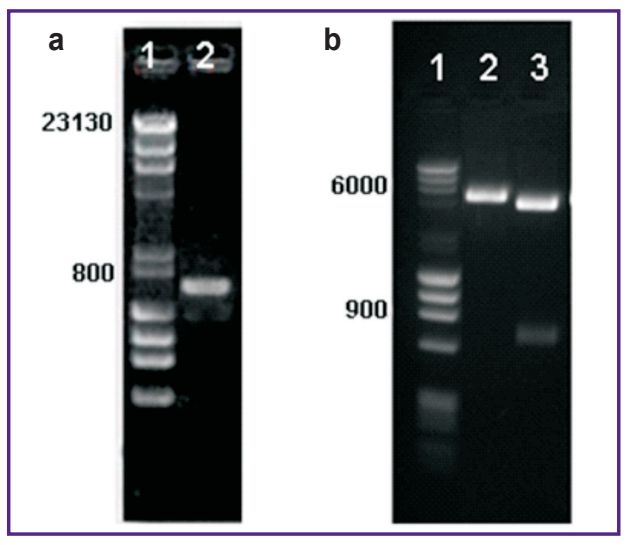

Figure 3. The qualitative analysis of the PCR and restriction steps by horizontal electrophoresis in agarose gel:

(a) PCR: 1 - DNA length marker, 2 - BDNF; (b) restriction: 1 - DNA length marker, 2 - restriction of AAV-Syn-BDNFEGFP with EcoRI, 3 - restriction of AAV-Syn-BDNF-EGFP with EcoRI and BamHI

cultures infected with the developed virus construct. To test the effectiveness of infection, immunocytochemical staining of cultures was performed using monoclonal antibody against BDNF (Figure 4). Notably, in cultures infected with the developed virus construct, the level of BDNF production was significantly higher than that in the intact cultures. This result implies that the developed virus construct effectively infects neuronal cells and stimulates the BDNF expression.
Since many viruses are known to kill neuronal cultures or impact the function of neural networks, the next stage of the study addressed the viability of primary hippocampal cell cultures; that was tested within 7 days after infection. It was found throughout the observation period that the number of dead cells in the experimental group of cultures did not differ from that in the intact controls, which was confirmed by the ANOVA comparison (Table 1).

To assess the effects of the virus construct on the neuronal network of the hippocampal cultures, the calcium-related cell function and the bioelectrical activity were assessed within 7 days upon the virus addition (experimental group) and compared with that of virusfree cultures.

Spontaneous bioelectrical activity was recorded immediately before the infection ( $7^{\text {th }}$ day of cultivation (7 DIV)) and then daily for 7 days (up to 14 DIV). According to previously published data [27-29], this period is crucial for the formation of network connections in dissociated cultures in vitro. According to our results, the developed construct did not inhibit the spontaneous bioelectrical activity of the hippocampal cultures. In both intact and infected cultures, the spontaneous packet activity continued throughout the observation period; this pattern is characteristic for the in vitro neural networks at this stage of their development.

It was also found that upon the addition of AAV-SynBDNF-EGFP on day 7 of culture growth, the level of spontaneous bioelectrical activity did not significantly change, according to any of the measured parameters 


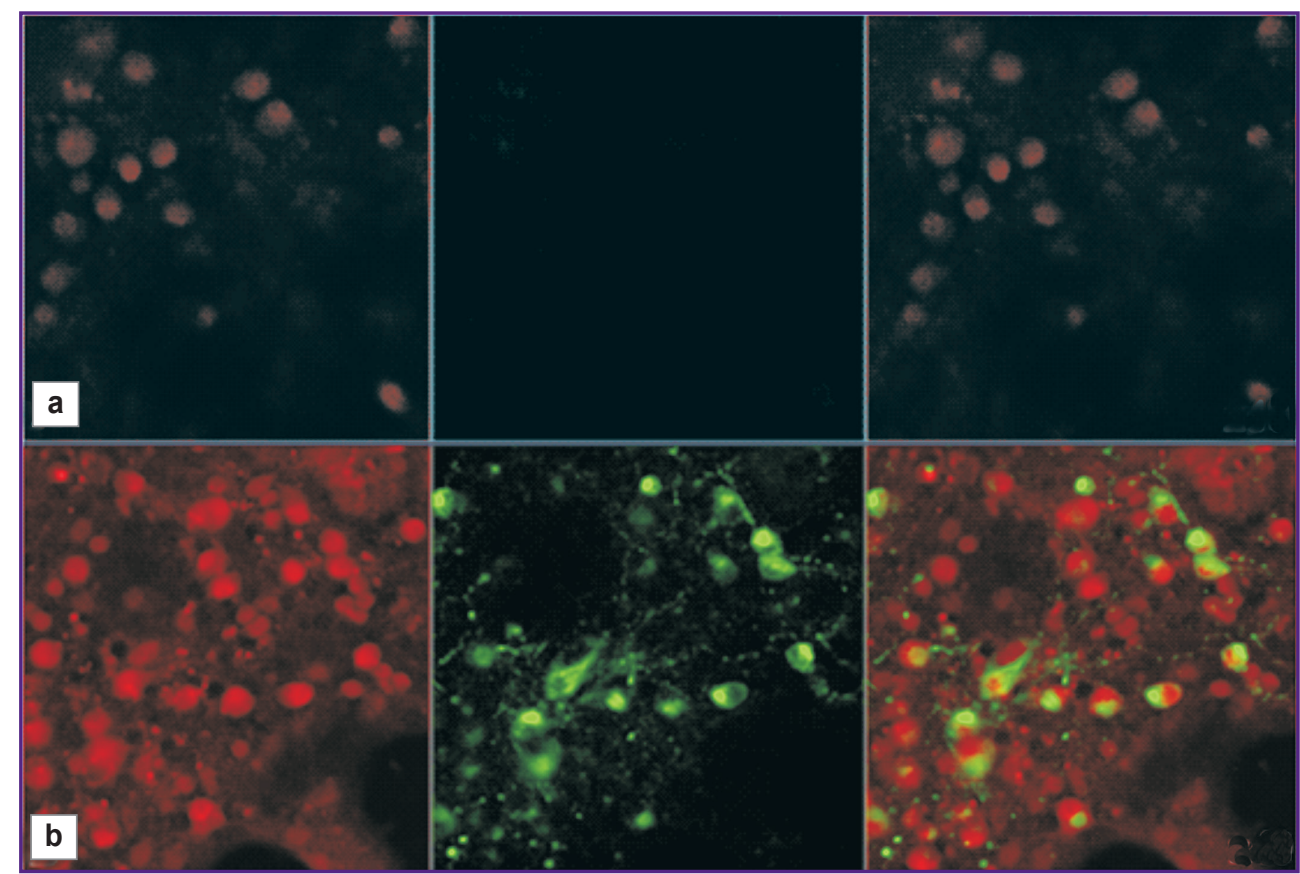

Figure 4. Immunocytochemical labeling of the BDNF protein in the primary culture of hippocampal cells infected with the AAV-Syn-BDNF-EGFP virus vector: the red channel - staining with antibody conjugated with the Alexa Flor 647 fluorescent label; the green channel - fluorescence of the green EGFP protein; (a) intact culture; (b) culture infected with AAV-Syn-BDNF-EGFP; 7 days after infection; $\times 40$

Table 1

The proportion of living cells (\%) in the hippocampal cultures infected

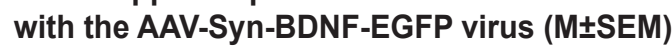

\begin{tabular}{|ccc|}
\hline $\begin{array}{c}\text { Days } \\
\text { after the infection } \\
\text { procedure }\end{array}$ & $\begin{array}{c}\text { Intact } \\
\text { cultures }\end{array}$ & $\begin{array}{c}\text { Cultures infected } \\
\text { with AAV-Syn-BDNF-EGFP }\end{array}$ \\
\hline 1 (8 DIV) & $96.44 \pm 1.89$ & $92.39 \pm 2.27$ \\
\hline $3(10$ DIV) & $92.35 \pm 2.13$ & $93.29 \pm 1.45$ \\
\hline $7(14$ DIV) & $90.28 \pm 3.32$ & $93.71 \pm 1.56$ \\
\hline
\end{tabular}

Note. The differences are statistically significant in comparison with intact cultures; ANOVA; $p<0.05$.

(the number of small network packets, the number of spikes in the packet) during 6 days after the infection procedure (Figure 5).

By day 7 after infection (14 DIV), there was some increase in the network activity in cultures with BDNF overexpression as compared with intact cultures, in terms of the number of spikes per a network packet (intact - 281.5 \pm 82.7 ; after infection with AAV-SynBDNF-EGFP - 402.3 \pm 111.3 ). The number of packets per $10 \mathrm{~min}$ did not significantly differ between the intact and infected cultures (intact cultures $-31.8 \pm 8.5$; infected cultures $-37.2 \pm 9.3$ ).

To assess the structural and functional state of neural networks at the cellular level, the multifactorial analysis of calcium homeostasis in the nervous tissue is most commonly used. Changes in the concentration of $\mathrm{Ca}^{2+}$ ions in the cytoplasm of nerve cells reflect the metabolic activity of both neurons and glia [25].

The parameters of calcium activity in the neuronal cultures (the number of cells exhibiting spontaneous calcium activity and the frequency and duration of calcium oscillations) were analyzed.

It was found that the developed virus did not change the proportions of cells that exhibited spontaneous calcium activity (Table 2) but increased the frequency of calcium events (control $-1.42 \pm 0.16$ oscillations per minute; infected cultures $-1.79 \pm 0.15$ oscillations per minute).

At the final stage of the study, the developed virus construct was tested for its neuroprotective potential under the conditions of hypoxia; for comparison, we tested the recombinant BDNF protein (Merk, France) added exogenously to the cell cultures. Modeling of hypoxia was initiated on day 7 (14 DIV) after the cultures had been infected with the virus. Recombinant BDNF at a concentration of $1 \mathrm{ng} / \mathrm{ml}$ was added to the culture medium 20 min prior to the onset of hypoxia. According to the results, the hypoxia caused a significant (ANOVA, $p<0.05)$ decrease in the number of living cells in the culture as assessed on the $7^{\text {th }}$ day of the post-hypoxic period (intact cells - 88.3 $\pm 2.3 \%$; post-hypoxic cells $62.9 \pm 1.8 \%)$. The study showed that both the exogenous 

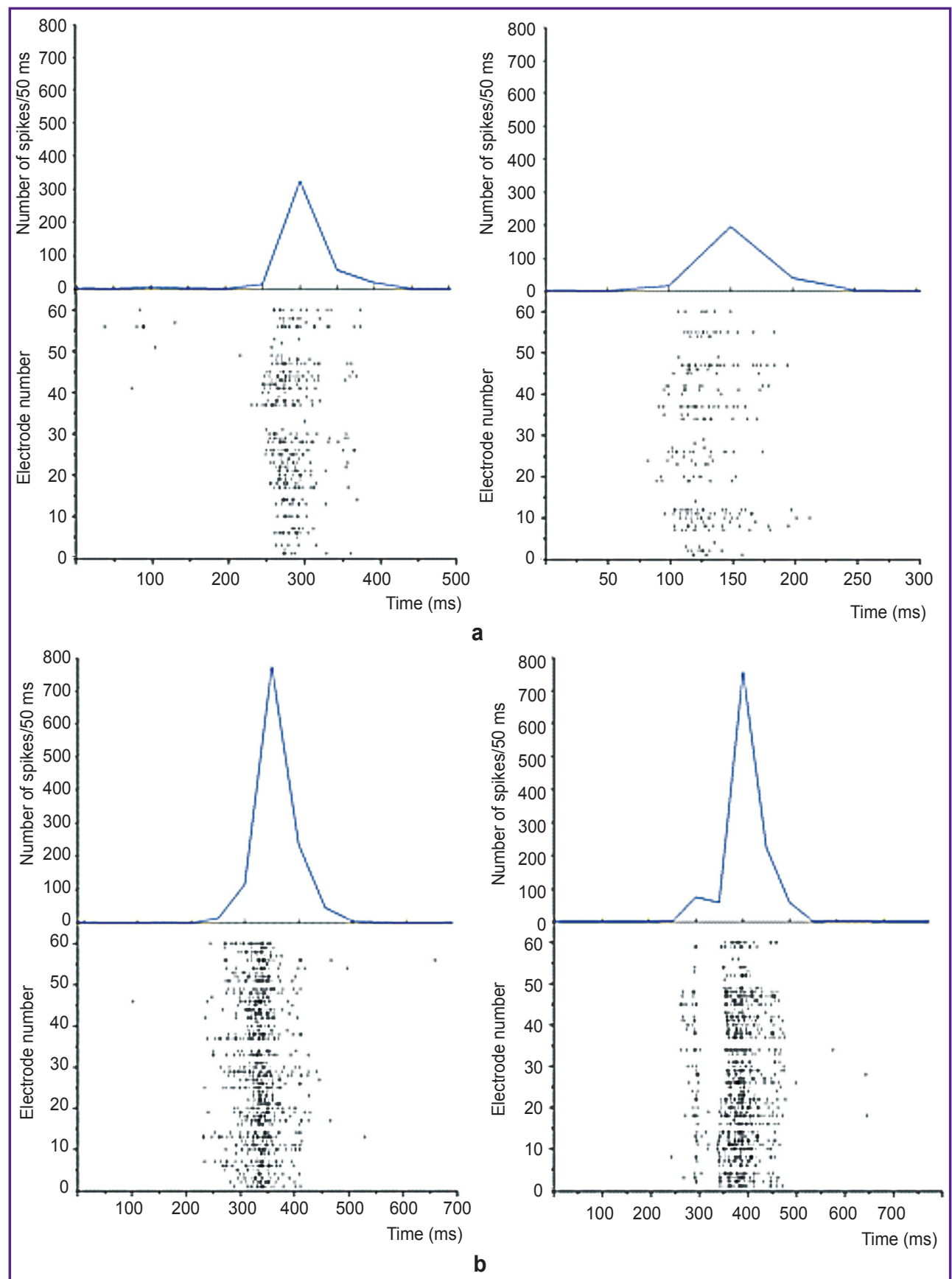

Figure 5. The raster graphs of spontaneous bioelectrical activity of the hippocampal cell culture in the post-hypoxic period:

(a) 1 day after infection (7 DIV); (b) 7 days after infection (14 DIV); left — intact culture; right culture infected with the AAV-Syn-BDNF-EGFP virus

Table 2

Major parameters of spontaneous calcium activity on day 7 (14 DIV) after the culture was infected with the AAV-Syn-BDNF-EGFP virus (M $\pm S E M)$

\begin{tabular}{lcc}
\hline \multicolumn{1}{c}{ Parameter } & Intact cultures & $\begin{array}{c}\text { Cultures infected } \\
\text { with AAV-Syn-BDNF-EGFP }\end{array}$ \\
\hline The number of active cells (\%) & $73.54 \pm 10.23$ & $83.10 \pm 11.55$ \\
\hline Duration of $\mathrm{Ca}^{2+}$ oscillations (s) & $7.80 \pm 0.55$ & $7.60 \pm 0.82$ \\
\hline Frequency of $\mathrm{Ca}^{2+}$ oscillations (oscillations per minute) & $1.42 \pm 0.16$ & $1.79 \pm 0.15$ \\
\hline
\end{tabular}




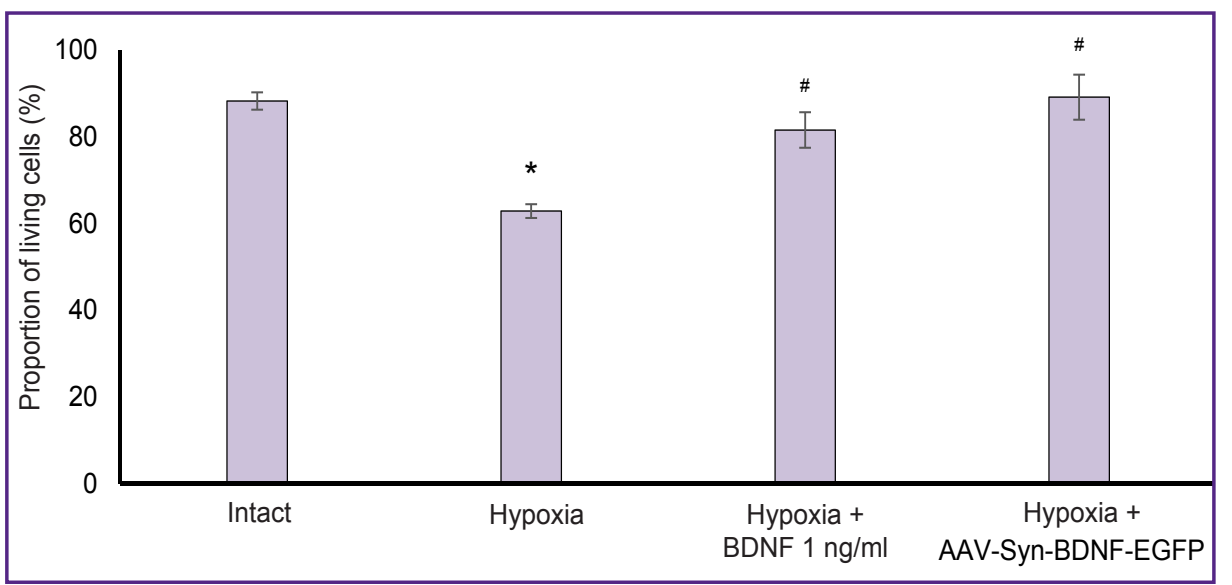

Figure 6. The proportion of living cells in the hippocampal cultures on day 7 after hypoxia exposure (14 DIV)

* The differences are statistically significant compared to control; \# compared to hypoxia; ANOVA; $p<0.05$

BDNF and the stimulation of intracellular BDNF expression (with the developed virus construct) helped prevent cell death in the post-hypoxic period. Thus, the proportion of living cells in the "hypoxia + BDNF" group was $81.6 \pm 4.1 \%$, and the "hypoxia + AAV-Syn-BDNFEGFP" group - 89.2 $\pm 5.2 \%$ (Figure 6).

\section{Discussion}

It has been shown $[1,4,6,11]$ that BDNF has a pronounced neuroprotective effect against detrimental factors of ischemia, including hypoxia. The use of recombinant BDNF increases the resistance of nerve cells to the damaging factors of ischemia both in vitro [14, 24] and in vivo [2, 14, 30, 31]. These results rationalized the potential use of neurotrophic protectors in the clinical management of ischemic brain damage. There are studies confirming the role of BDNF in the CNS regeneration after the death of a significant part of functionally significant neurons [32]. However, systemic application of recombinant proteins causes just a temporary effect, which requires their permanent supply to the body. Therefore, targeted gene delivery to specific areas of the nervous system in the injury zone can be much more effective in the long-term treatment of CNS injuries [19, 20].

As a result of the present study, we have developed a virus construct containing the sequence of the BDNF gene that allows one to increase the expression of BDNF in brain neurons. In this report, we describe the functional capacity of this experimental product.

It is known that during cell cultivation, the newly formed neural networks undergo several characteristic changes in their morphology and functions [27-29]. Our in vitro study showed that the overexpression of BDNF had no significant effects on the bioelectrical or calcium-associated activities; it is, therefore, safe to use this approach to restore brain functions after ischemic damage. The developed virus preparation is not cytotoxic and does not negatively affect the hippocampal cell cultures.

The conducted experiments show that an increased expression of BDNF allows reducing the death of nerve cells caused by hypoxia in vitro. The demonstrated neuroprotective effect is comparable to the effect of the exogenously added recombinant BDNF. The obtained results provide the rationale for a further development of this method aiming to protect the brain against ischemic damage. The proposed approach may also find its use in the treatment of neurodegenerative diseases, where hypoxia plays a key role in the pathogenesis.

\section{Conclusion}

The adeno-associated virus vector AAV-Syn-BDNFEGFP, carrying the sequence of the BDNF gene, has been designed to increase the expression of the BDNF neurotrophic factor in the brain. Primary cultures of mouse hippocampal cells infected with the developed vector increased their production of BDNF. The presence of this virus construct did not adversely affect the viability or functional activity of the neural networks formed in these cells cultures. The overexpression of BDNF increased the neuroprotective potential of cultured cells subjected to in vitro hypoxia.

Financial support. The study was supported by the state-sponsored projects 17.3335.2017/IF and 6.6379.2017/CU aimed at producing a virus construct, and also by the Russian Science Foundation project 17-75-10149 awarded to study the construct-induced neuroprotection.

Conflict of interest. The authors declare they have no conflicts of interest that need to be reported. 


\section{References}

1. Chen A., Xiong L.J., Tong Y., Mao M. The neuroprotective roles of BDNF in hypoxic ischemic brain injury. Biomed Rep 2013; 1(2): 167-176, https://doi.org/10.3892/ br.2012.48.

2. Harris N.M., Ritzel R., Mancini N.S., Jiang Y., Yi X., Manickam D.S., Banks W.A., Kabanov A.V., McCullough L.D., Verma R. Nano-particle delivery of brain derived neurotrophic factor after focal cerebral ischemia reduces tissue injury and enhances behavioral recovery. Pharmacol Biochem Behav 2016; 150-151: 48-56, https://doi.org/10.1016/j. pbb.2016.09.003.

3. Kotlęga D., Peda B., Zembroń-Łacny A., GołąbJanowska M., Nowacki P. The role of brain-derived neurotrophic factor and its single nucleotide polymorphisms in stroke patients. Neurol Neurochir Pol 2017; 51(3): 240-246, https://doi.org/10.1016/j.pjnns.2017.02.008.

4. Zhao H., Alam A., San C.Y., Eguchi S., Chen Q., Lian Q., Ma D. Molecular mechanisms of brain-derived neurotrophic factor in neuro-protection: recent developments. Brain Res 2017; 1665: 1-21, https://doi.org/10.1016/j. brainres.2017.03.029.

5. Douglas-Escobar M., Rossignol C., Steindler D., Zheng T., Weiss M.D. Neurotrophin-induced migration and neuronal differentiation of multipotent astrocytic stem cells in vitro. PLoS One 2012; 7(12): e51706, https://doi.org/10.1371/ journal.pone.0051706.

6. Skaper S.D. Neurotrophic factors: an overview. Methods Mol Biol 2018; 1727: 1-17, https://doi.org/10.1007/978-1-49397571-6_1.

7. Martin J.L., Finsterwald C. Cooperation between BDNF and glutamate in the regulation of synaptic transmission and neuronal development. Commun Integr Biol 2011; 4(1): 14-16, https://doi.org/10.4161/cib.13761.

8. Rose C.R., Blum R., Kafitz K.W., Kovalchuk Y., Konnerth A. From modulator to mediator: rapid effects of BDNF on ion channels. BioEssays 2004; 26(11): 1185-1194, https:// doi.org/10.1002/bies.20118.

9. Cunha C., Brambilla R., Tomas K.L. A simple role for BDNF in learning and memory? Front Mol Neurosci 2010; 3: 1, https://doi.org/10.3389/neuro.02.001.2010.

10. Kowiański P., Lietzau G., Czuba E., Waśkow M., Steliga A., Moryś J. BDNF: a key factor with multipotent impact on brain signaling and synaptic plasticity. Cell Mol Neurobiol 2018, 38(3): 579-593, https://doi.org/10.1007/s10571-0170510-4.

11. Vedunova M.V., Sakharnova T.A., Mitroshina E.V., Shishkina T.V., Astrakhanova T.A., Mukhina I.V. Antihypoxic and neuroprotective properties of BDNF and GDNF in vitro and in vivo under hypoxic conditions. Sovremennye tehnologii $v$ medicine 2014; 6(4): 38-47.

12. Zhang Y., Pardridge W.M. Neuroprotection in transient focal brain ischemia after delayed intravenous administration of brain-derived neurotrophic factor conjugated to a blood-brain barrier drug targeting system. Stroke 2001; 32(6): 1378-1384, https://doi.org/10.1161/01.str.32.6.1378.

13. Neumann J.T., Thompson J.W., Raval A.P., Cohan C.H., Koronowski K.B., Perez-Pinzon M.A. Increased BDNF protein expression after ischemic or PKC epsilon preconditioning promotes electrophysiologic changes that lead to neuroprotection. J Cereb Blood Flow Metab 2015; 35(1): 121-130, https://doi.org/10.1038/jcbfm.2014.185.
14. Huang W., Meng F., Cao J., Liu X., Zhang J., Li M. Neuroprotective role of exogenous brain-derived neurotrophic factor in hypoxia-hypoglycemia-induced hippocampal neuron injury via regulating Trkb/MiR134 signaling. J Mol Neurosci 2017; 62(1): 35-42, https://doi.org/10.1007/s12031-0170907-z.

15. Berretta A., Tzeng Y.C., Clarkson A.N. Post-stroke recovery: the role of activity-dependent release of brain-derived neurotrophic factor. Expert Rev Neurother 2014; 14(11): 13351344, https://doi.org/10.1586/14737175.2014.969242.

16. Mang C.S., Campbell K.L., Ross C.J., Boyd L.A. Promoting neuroplasticity for motor rehabilitation after stroke: considering the effects of aerobic exercise and genetic variation on brain-derived neurotrophic factor. Phys Ther 2013; 93(12): 1707-1716, https://doi.org/10.2522/ptj.20130053.

17. Liu S., Sandner B., Schackel T., Nicholson L., Chtarto A., Tenenbaum L., Puttagunta R., Müller R., Weidner N., Blesch A. Regulated viral BDNF delivery in combination with Schwann cells promotes axonal regeneration through capillary alginate hydrogels after spinal cord injury. Acta Biomater 2017; 60: 167-180, https://doi.org/10.1016/j. actbio.2017.07.024.

18. Kimura A., Namekata K., Guo X., Harada C., Harada T. Neuroprotection, growth factors and BDNF-TrkB signalling in retinal degeneration. Int J Mol Sci 2016; 17(9): 1584, https:// doi.org/10.3390/ijms17091584.

19. Igarashi T., Miyake K., Kobayashi M., Kameya S., Fujimoto C., Nakamoto K., Takahashi H., Igarashi T., Miyake N., lijima O., Hirai Y., Shimada T., Okada T., Takahashi H. Tyrosine triple mutated AAV2-BDNF gene therapy in a rat model of transient IOP elevation. Mol Vis 2016; 22: 816-826.

20. Katsu-Jiménez Y., Loría F., Corona J.C., Díaz-Nido J. Gene transfer of brain-derived neurotrophic factor (BDNF) prevents neurodegeneration triggered by FXN deficiency. Mol Ther 2016; 24(5): 877-889, https://doi.org/10.1038/ mt.2016.32.

21. Iwasaki Y., Negishi T., Inoue M., Tashiro T., Tabira T., Kimura N. Sendai virus vector-mediated brain-derived neurotrophic factor expression ameliorates memory deficits and synaptic degeneration in a transgenic mouse model of Alzheimer's disease. J Neurosci Res 2012; 90(5): 981-989, https://doi.org/10.1002/jnr.22830.

22. Dekeyster E., Geeraerts E., Buyens T., Van den Haute C., Baekelandt V., De Groef L., Salinas-Navarro M., Moons L. Tackling glaucoma from within the brain: an unfortunate interplay of BDNF and TrkB. PLOS One 2015; 10(11): e0142067, https://doi.org/10.1371/journal. pone.0142067.

23. Yu S.J., Tseng K.Y., Shen H., Harvey B.K., Airavaara M., Wang Y. Local administration of AAV-BDNF to subventricular zone induces functional recovery in stroke rats. PLoS One 2013; 8(12): e81750, https://doi.org/10.1371/journal. pone.0081750.

24. Vedunova M.V., Mishchenko T.A., Mitroshina E.V., Mukhina I.V. TrkB-mediated neuroprotective and antihypoxic properties of brain-derived neurotrophic factor. Oxid Med Cell Longev 2015; 2015: 453901, https://doi. org/10.1155/2015/453901.

25. Zakharov Yu.N., Korotchenko S.A., Kalintseva Ya.I., Potanina A.V., Mitroshina E.V., Vedunova M.V., Mukhina I.V. Fluorescence analysis of the metabolic activity patterns of a neuronal-glial network. Journal of Optical Technology 2012; 79(6): 348-351, https://doi.org/10.1364/jot.79.000348. 


\section{ADVANCED RESEARCHES}

26. Pimashkin A., Kastalskiy I., Simonov A., Koryagina E., Mukhina I., Kazantsev V. Spiking signatures of spontaneous activity bursts in hippocampal cultures. Front Comput Neurosci 2011; 5: 46, https://doi.org/10.3389/fncom.2011.00046.

27. Shirokova O.M., Frumkina L.E., Vedunova M.V., Mitroshina E.V., Zakharov Y.N., Khaspekov L.G., Mukhina I.V. Morphofunctional patterns of neuronal network developing in dissociated hippocampal cell cultures. Sovremennye tehnologii $v$ medicine $2013 ; 2:$ 6-13.

28. Agrba E.A., Mukhina I.V. Spatio-temporal characteristics of neuronal network activity of primary hippocampal cultures. Vestnik Nizhegorodskogo universiteta im. N.I. Lobachevskogo 2013; 4(1): 139-144.

29. Mitroshina E.V., Vedunova M.V., Shirokova O.M., Zakharov Yu.N., Kalintseva Ya.I., Mukhina I.V. Assessment of functional state dynamics of dissociated hippocampal cell culture in vitro. Vestnik Nizhegorodskogo universiteta im. N.I. Lobachevskogo 2011; 2(2): 283-286.

30. Ramos-Cejudo J., Gutiérrez-Fernández M., Otero-Ortega L., Rodríguez-Frutos B., Fuentes B., Vallejo-Cremades M.T., Hernanz T.N., Cerdán S., DíezTejedor E. Brain-derived neurotrophic factor administration mediated oligodendrocyte differentiation and myelin formation in subcortical ischemic stroke. Stroke 2015; 46(1): 221-228, https://doi.org/10.1161/strokeaha.114.006692.

31. Hernandez-Torres V., Gransee H.M., Mantilla C.B., Wang Y., Zhan W.Z., Sieck G.C. BDNF effects on functional recovery across motor behaviors after cervical spinal cord injury. J Neurophysiol 2017; 117(2): 537-544, https://doi. org/10.1152/jn.00654.2016.

32. Vedunova M.V., Mishchenko T.A., Shishkina T.V., Mukhina I.V. Method of partial restoration of functional activity of neural networks in vitro in conditions of considerable damage. Patent RU 2594065. 2016. 